\title{
Effect of Laser Surface Treatment on the Corrosion Behavior of FeCrAl-Coated TZM Alloy
}

\author{
Jeong-Min Kim ${ }^{1}{ }^{*}$, Tae-Hyung Ha ${ }^{1}$, Joon-Sik Park ${ }^{1}$ and Hyun-Gil Kim ${ }^{2}$ \\ 1 Department of Advanced Materials Engineering, Hanbat National University, 125 Dongseo-daero, \\ Yuseong-gu, Daejeon 34158, Korea; htman15@naver.com (T.-H.H.); jsphb@hanbat.ac.kr (J.-S.P.) \\ 2 Light Water Reactor Fuel Technology Division, Korea Atomic Energy Research Institute, \\ 989-111 Daedeok-daero, Yuseong-gu, Daejeon 34057, Korea; hgkim@kaeri.re.kr \\ * Correspondence: jmk7475@hanbat.ac.kr; Tel.: +82-42-821-1235; Fax: +82-42-821-1592
}

Academic Editor: Ana Sofia Ramos

Received: 6 December 2015; Accepted: 27 January 2016; Published: 29 January 2016

\begin{abstract}
The current study involves the coating of Titanium-Zirconium-Molybdenum (TZM) alloy with $\mathrm{FeCrAl}$ through plasma thermal spraying which proved effective in improving the oxidation resistance of the substrate. A post-laser surface melting treatment further enhanced the surface protection of the TZM alloy. Oxidation tests conducted at $1100{ }^{\circ} \mathrm{C}$ in air indicated that some Mo oxides were formed at the surface but a relatively small amount of weight reduction was observed for FeCrAl-coated TZM alloys up to $60 \mathrm{~min}$ of treatment. The post-laser surface treatment following the plasma thermal spray process apparently delayed the severe oxidation process and surface spalling of the alloy. It was suggested that the slow reduction in weight in the post-laser-treated specimen was related to fewer defects in the coating layer. It was also found that a surface reaction layer formed through the diffusion of Fe into the Mo alloy substrate at high temperature. The layer mainly consisted of Fe-saturated Mo and FeMo intermetallic compounds. In order to observe the corrosion behavior of the laser-treated alloy in $3.5 \% \mathrm{NaCl}$ solution, electrochemical characteristics were also investigated. A proposed equivalent circuit model for the specimen indicated localized corrosion of coated alloy with some permeable defects in the coating layer.
\end{abstract}

Keywords: Mo alloy; FeCrAl; plasma thermal spray; laser treatment

\section{Introduction}

Due to excellent high temperature properties, Mo alloys are used in a large number of elevated temperature applications in the aerospace and nuclear industries [1]. However, a primary drawback of these alloys is susceptibility to high temperature oxidation because volatile $\mathrm{MoO}_{3}$ is formed in the oxidizing environment at a high temperature such as $873^{\circ} \mathrm{C}$ [2]. Therefore, some protective coatings are often necessary to protect the surface of Mo alloys from oxidation [3-5]. To this end, FeCrAl alloy can be applied as a coating layer to the surface of Mo alloys since it can withstand a temperature as high as $1400^{\circ} \mathrm{C}[6,7]$. The thermal spraying method has been sucessfully employed to improve the oxidation resistance of substrate alloys, and the process has several advantages, such as low cost and simple operation $[4,5]$. However, thermal spray techniques are often implicated in introducing defects in the coating, such as pores and weak interfacial bondings [7].

Post-treatments such as laser surface melting following the thermal spray can be useful to enhace the interface stability and resultant oxidation resistance. It has been reported that relatively high porosity, as well as poor adhesion in various coating/substrate systems, could be modified by such post-treatments. The laser surface melting process could significantly enhance the adhesion of the metallic coating layer to a substrate and reduce microdefects in the coating [8-13]. 
In the current study, we primarily focused on increasing the stability of the protective FeCrAl coating layer by at least a few hours at high temperatures above $1000{ }^{\circ} \mathrm{C}$, which would be highly significant from an industrial standpoint. Even if the treatment time at high temperatures is not long, some interdiffusion occurs between the coating and the substrate. Such a diffusion process may cause the formation of MoFe intermetallic compounds, thereby resulting in a change in the microstructure of the $\mathrm{FeCrAl} / \mathrm{Mo}$ system at the high temperature. This issue has also been addressed in the current work. Furthermore, the general corrosion behavior of FeCrAl-coated Mo alloy after the laser treatment has been also investigated.

\section{Experimental Section}

In the current research TZM Mo alloy was used as the substrate. FeCrAl alloy with a composition of $\mathrm{Fe}-20$ wt. \% Cr-5 wt. \% Al was deposited on the surface of sand-blasted and ultrasonic-cleaned TZM substrate via air plasma thermal spray process. A mixture of $\mathrm{Ar}$ and $\mathrm{H}_{2}$ was used as the plasma gas and argon was used as the powder carrier gas. The plasma thermal spraying process parameters employed in this study are as follows: $400 \mathrm{~A}$, Ar gas pressure of $100 \mathrm{MPa}, \mathrm{H}_{2}$ gas pressure of $6 \mathrm{MPa}$, and spray distance of $100 \mathrm{~mm}$. Some of the as-sprayed $\mathrm{FeCrAl}$ coatings were surface-treated by using a continuous wave (CW) diode laser with a maximum power of $300 \mathrm{~W}$ (PF-1500F model; HBL Co., Daejeon, Korea) and a powder supplier (Pwp14Y04K model; Yesystem Co., Daejeon, Korea). The laser process parameters, such as laser power, scanning speed, and powder injection, were set up based on a previous work [14]. The optimized applied power for the current research was $180 \mathrm{~W}$, the scanning speed was $8 \mathrm{~mm} / \mathrm{s}$, and powder injection rate was $6.5 \mathrm{~g} / \mathrm{min}$. To prevent specimens from oxidation during the process, argon was continuously supplied into the melting zone.

Oxidation behaviors of $\mathrm{FeCrAl}$-coated specimens were investigated in air at $1100{ }^{\circ} \mathrm{C}$. The specimens were $10 \times 10 \times 7 \mathrm{~mm}$ in size and were isothermally heated in an electric resistance furnace (PCAM Korea Co., Daejeon, Korea). The oxidation resistance was evaluated by measuring the average weight changes with respect to the holding time for the oxidized specimens. In order to observe the microstructural changes of the laser-treated coating layer during the high temperature oxidation, the coating specimen was isothermally heated at $1100{ }^{\circ} \mathrm{C}$ for $5 \mathrm{~h}$ under argon atmosphere. Microstructural analyses were performed using a scanning electron microscope (SEM, JEOL, JSM-5610, Tokyo, Japan), equipped with energy dispersive X-ray spectrometer (EDS, JEOL, Tokyo, Japan), and X-ray diffractometer (XRD, Rigaku, Smartlab, Tokyo, Japan). Electrochemical measurements were performed using a potentiostat and an electro impedance spectroscopy (EIS) analysis software (ZIVE SP1, WONATECH, Seoul, Korea). Saturated calomel electrode was used as the reference electrode and platinum plate was used as the counter-electrode. $\mathrm{NaCl}$ solution ( $3.5 \mathrm{wt}$. \%) was used as the electrolyte and the potential scan rate for polarization tests was $1 \mathrm{mV} / \mathrm{s}$.

\section{Results and Discussion}

\subsection{Oxidation Resistance of FeCrAl-Coated TZM Alloy at $1100^{\circ} \mathrm{C}$}

Figure 1 shows cross-sectional SEM images of plasma thermal sprayed FeCrAl coatings on TZM alloys before and after the laser surface treatment. Comparatively sound coating layers could be observed in both the as-sprayed and the post-laser treated specimens. A somewhat nonuniform thickness of the $\mathrm{FeCrAl}$ coating layer was found after the laser surface melting; however, the interface appeared to be a little more compact in that case. The darker area, which was aluminum-rich based on the SEM-EDS analyses, seen in the FeCrAl coating layers with and without the post-treatment, implied that some segregation occurred during the coating processes. Although the area looks a little darker in the as-sprayed specimen, the darker area was found also to be aluminum-rich.

The oxidation resistance of the $\mathrm{FeCrAl}$-coated specimens at $1100{ }^{\circ} \mathrm{C}$ was measured as the percent weight loss with respect to the reference, as compared in Figure 2. It appears that the coating layers on the surface of the Mo alloys were consistently detached from the substrates, especially after a long 
exposure time. Initially, the amount of weight reduction for both the specimens remained small up to $60 \mathrm{~min}$, after which significant weight loss was observed. This indicated that the FeCrAl coatings, regardless of preparation route, clearly protected the substrate because significant oxidation and spalling of the substrate TZM alloys without any coating are known to occur almost instantly at high temperatures [15]. In our samples, the oxidation behavior appeared to be dependent on whether the post-laser treatment was conducted or not for long exposure times. In comparison with the plasma thermal spray, the post-laser surface treatment following the spray showed a slower weight reduction rate. When the FeCrAl-coated Mo alloys are exposed to a high temperature, for instance $1100{ }^{\circ} \mathrm{C}$, the initial oxidation will take place mainly through the defect areas, such as pores and cracks in the coating layers. Therefore, it can be concluded that the whole oxidation process was relatively slower in the laser-treated specimen with reduced porosity in the FeCrAl coating. Another reason can be related to the bonding characteristics of the interface. The interface between the as-sprayed coating and the substrate was mechanically bonded, while the interfacial bonding has been reported to become stronger metallurgically after the laser treatment [8]. Quite a few research results showed that laser treatments reduced the porosity and strengthened the coating adhesion in many coating/substrate systems [8-13].
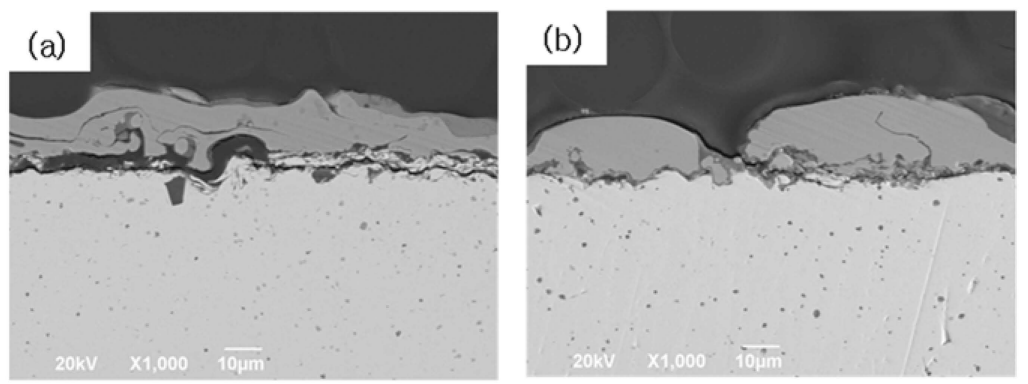

Figure 1. Cross-sectional microstructures of FeCrAl plasma thermal spray-coated TZM alloy: (a) as-sprayed; (b) after the laser surface melting process.

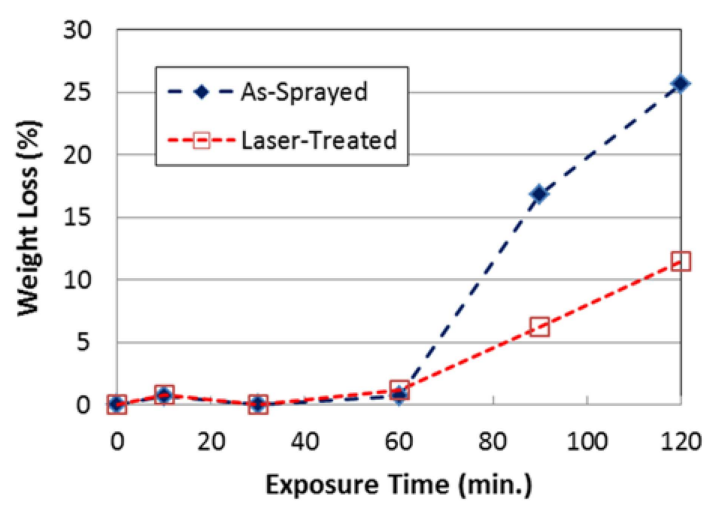

Figure 2. Oxidation behaviors of FeCrAl plasma thermal spray-coated TZM alloys before and after the laser surface treatment.

Figure 3 shows the typical surface appearance of oxidized specimens prepared with and without the post-laser surface treatment. Severely damaged surfaces with a lot of $\mathrm{MoO}_{3}$ phases were observed in the as-sprayed samples, while a relatively smooth surface, except for some small portions of damaged areas, was present in the post-laser-treated specimen. These observations implied that the oxidation of Mo substrate proceeded preferentially through the defect areas of the coating layer. If Mo oxides are formed on the surface of a substrate, the oxidized layer will expand and volatilize. Once some cracks are formed at the coating/substrate interface, the oxidation process becomes more facilitated. 
The XRD analysis results (Figure 4) showed various oxides, such as $\mathrm{MoO}_{3}, \mathrm{Fe}_{2} \mathrm{O}_{3}$, and $\mathrm{Cr}_{2} \mathrm{O}_{3}$. $\mathrm{Cr}$ and $\mathrm{Al}$ oxides are generally known to protect metallic materials effectively from oxidation [16]. $\mathrm{Al}$ oxides were not clearly found, possibly because of the relatively small amount of $\mathrm{Al}$ additions. It is noteworthy that $\mathrm{MoO}_{3}$ phases were also formed on the surface of the laser-treated specimen even though its surface morphology appeared to be quite different from that of the as-sprayed ones. Since fewer defect areas were observed in the coating layer on the surface of the laser-treated alloy, it could be harder for oxygen to diffuse through the coating layer. However, the laser-treated coating layers were also found to contain some defects.
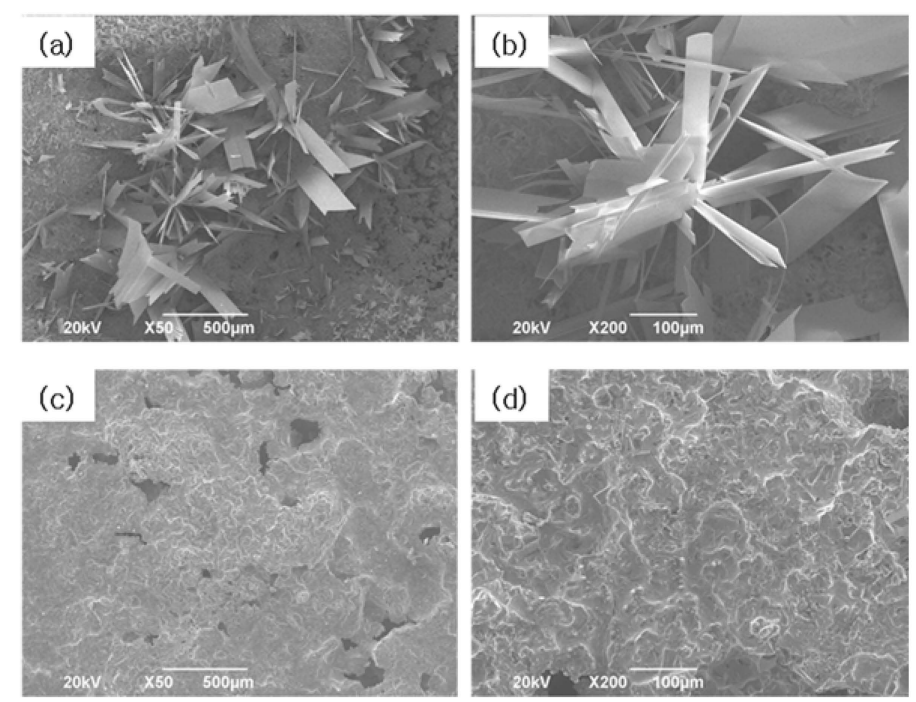

Figure 3. Surface morphologies of FeCrAl plasma thermal spray-coated TZM alloys: (a,b) as-sprayed; (c,d) after the laser treatment.

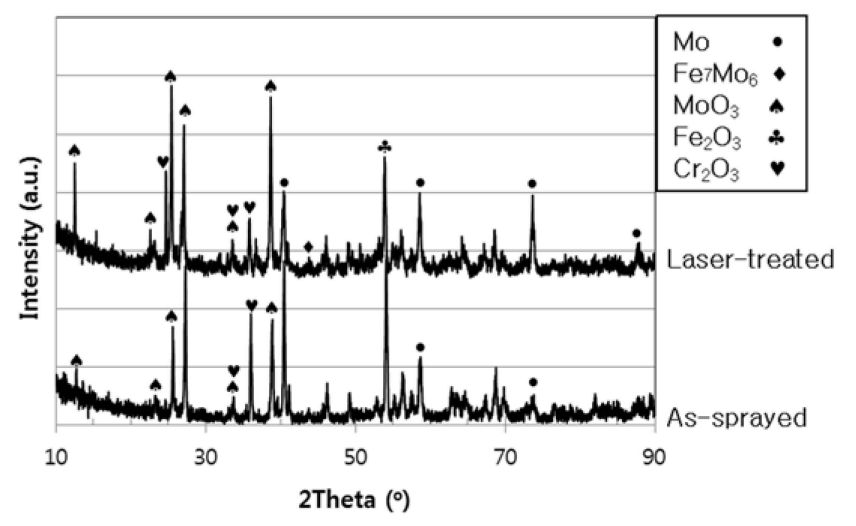

Figure 4. XRD analysis results of surfaces of oxidation test specimens.

\subsection{Microstructural Variations of FeCrAl-Coated TZM Alloy at $1100{ }^{\circ} \mathrm{C}$}

The microstructure of the coating layer is expected to change when it is exposed to high temperatures which in turn should affect the oxidation resistance of FeCrAl-coated alloy. As previously mentioned, the initial oxidation process depended mainly on the defect areas of the coating layers. However, after a certain period of time, the Mo substrate would become exposed to air because of not only the severe spalling of surface coating layers that occurs but also the interdiffusion that takes place between the Mo alloy substrate and the FeCrAl coating layer. Then Mo oxides are formed in large quantities, resulting in severely damaged surfaces and spalling. In order to understand the microstructural changes of the FeCrAl coating layers during high temperature 
oxidation, the laser-treated specimen was isothermally heated at the same temperature $\left(1100{ }^{\circ} \mathrm{C}\right)$ under Ar atmosphere.

As shown in Figure 5, some interfacial reactions occurred in the isothermally heated specimen. Diffusion of iron into the Mo matrix apparently occurred during the isothermal heating at $1100{ }^{\circ} \mathrm{C}$, and SEM-EDS analyses indicated that the reaction layer consisted of mainly two different areas: low $\mathrm{Fe}$ and high Fe regions. The dominant low Fe area is represented as the Mo phase containing about $10 \% \mathrm{Fe}$. The maximum solubility of Fe in Mo is about 31 at. $\%$ at $1611^{\circ} \mathrm{C}$, but it is sharply reduced with a decrease in temperature and the solubility at $1100{ }^{\circ} \mathrm{C}$ is about $10 \%$. Some MoFe intermetallic compounds might have formed from the supersaturated Mo matrix either during the heating or the cooling. It has been reported that $\mu$-phase and $\sigma$-phase can form between the Fe coating layer and the Mo substrate [17]. Since the isothermal heating was carried out at $1100^{\circ} \mathrm{C}$, the high Fe area was postulated to be $\mathrm{Fe}_{7} \mathrm{Mo}_{6} \mu$-phase. According to the SEM-EDS analysis results it is suggested that $\mathrm{Fe}$ diffused into the Mo substrate nonuniformly, mainly through the less dense areas. When Fe exceeded its solubility limit in the Mo matrix at a certain temperature, the $\mathrm{Fe}_{7} \mathrm{Mo}_{6}$ intermetallic compound was finally formed from the supersaturated matrix. Figure 6 also indicates that the MoFe phases were formed among the low Fe-containing Mo phases. Cr was uniformly distributed in the reacted surface region, which was attributed to the fact that Mo and $\mathrm{Cr}$ show miscibility in both solid and liquid states.

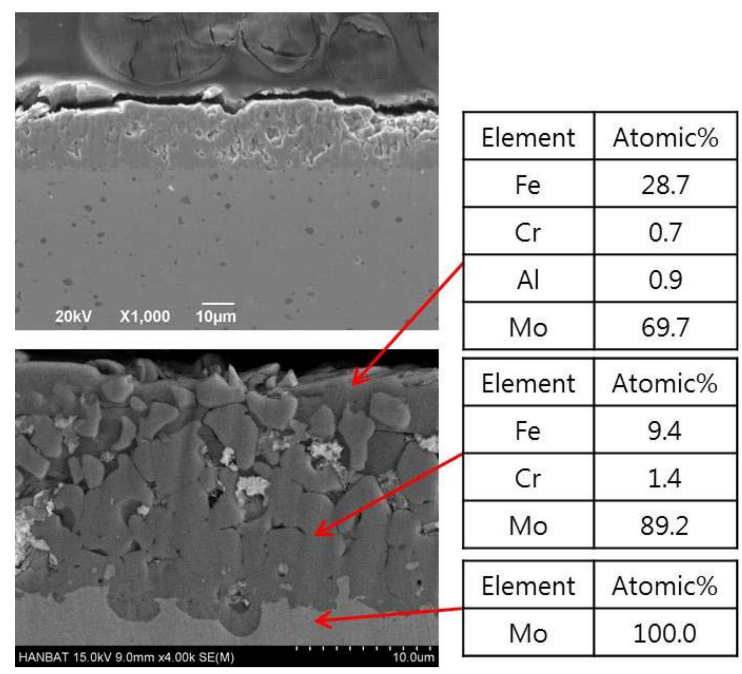

Figure 5. Cross-sectional microstructure of the post-laser-treated TZM alloy that was isothermally heated at $1100{ }^{\circ} \mathrm{C}$.
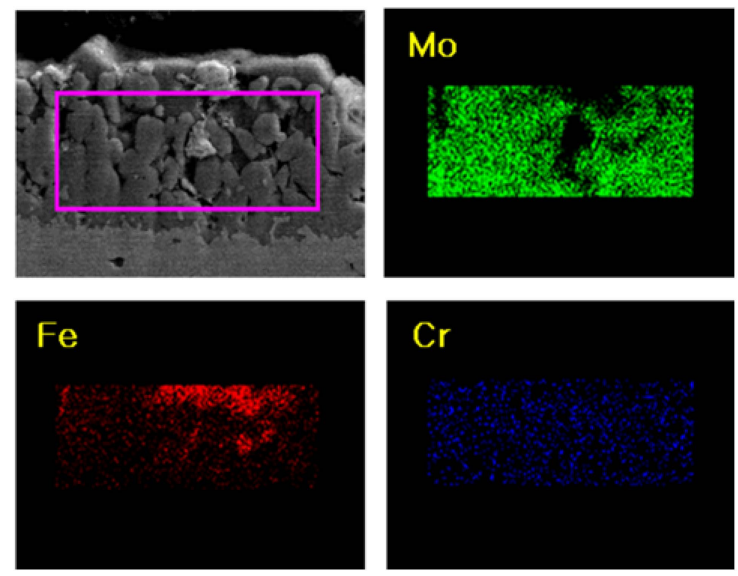

Figure 6. SEM micrograph and EDS mapping of the post-laser-treated TZM alloy that was isothermally heated at $1100{ }^{\circ} \mathrm{C}$. 


\subsection{Corrosion Behavior of FeCrAl-Coated TZM Alloys in $3.5 \% \mathrm{NaCl}$}

Although the oxidation behavior of FeCrAl-coated Mo alloys at high temperature is focused on in the present research, the corrosion resistance of the alloys in $3.5 \% \mathrm{NaCl}$ solution is also industrially important. As shown in Figure 7, the $E_{\text {corr. }}$ for the post-laser-treated specimen was a little more noble than that for the as-sprayed specimen. The corrosion current density for both specimens was found to be similar, even though the accuracy may not be high due to a lack of linearity in the plots. Because of the lower corrosion potential and the similar corrosion current density of the as-sprayed specimen obtained from the curves, a little lower corrosion resistance can be considered for the as-sprayed than the post-laser-treated specimen.

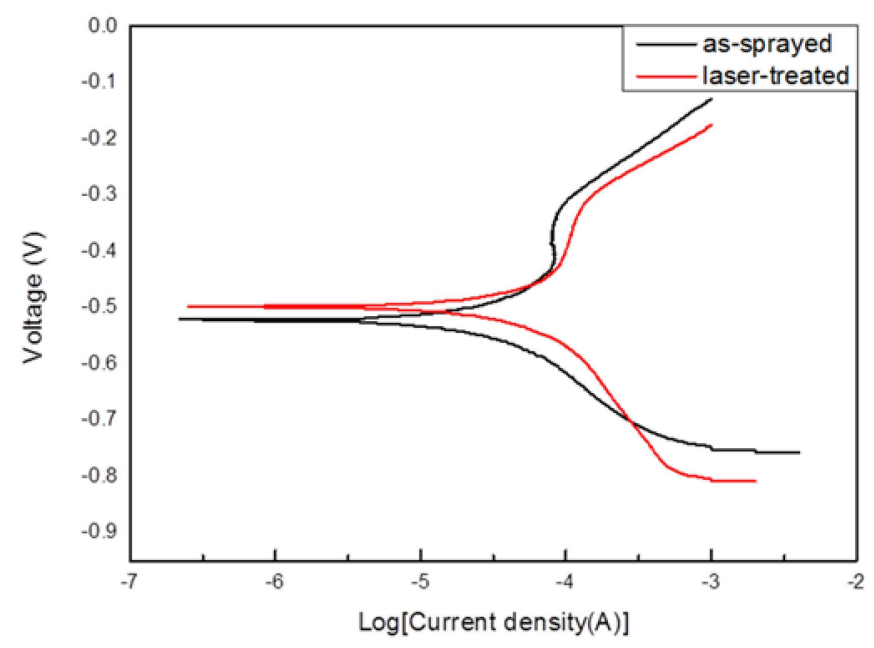

Figure 7. Potentiodynamic polarization scans for $\mathrm{FeCrAl}$ plasma spray-coated Mo alloys in $3.5 \% \mathrm{NaCl}$ solution with and without the post-laser treatment.

These polarization curves were obtained after seven days' immersion in $3.5 \% \mathrm{NaCl}$ solution and some variations in the potential were observed. The variations in potential were reported to be due to irregular repassivation and depassivation processes [18]. Since $E_{\text {corr. }}$ for the substrate TZM alloy was measured at about $-443 \mathrm{mV}$, the substrate was apparently more noble than the $\mathrm{FeCrAl}$ coating layers, regardless of whether the post-laser treatment was perfomed or not. This means that the substrate itself will be protected even if it is exposed to the solution through defect areas in the coating layers.

Figure 8 indicates a proposed equivalent circuit model for the laser-treated specimen immersed in $3.5 \% \mathrm{NaCl}$ solution for seven days. An equivalent model typically represents localized corrosion of the coated alloy containing some permeable defects in the coating layer [19-21]. Rs corresponds to the solution resistance of the electrolyte between the reference and the working electrodes. $Q 1$ is the coating capacitance and $R 1$ is the pore electrical resistance to the ionic current through the pores. $Q 2$ and $R 2$ represent the polarization resistance and capacitance of the Mo alloy, respectively. A constant phase element (CPE) is often known to be a practical way to describe the aforementioned capacitance [19]. The values of the parameters for the equivalent circuit in Figure 8 are listed in Table 1.

Table 1. Electrochemical parameters obtained from EIS spectra of the post-laser-treated TZM alloy immersed in $3.5 \% \mathrm{NaCl}$ solution for seven days.

\begin{tabular}{cccccc}
\hline Parameters & $R_{\mathrm{s}}\left(\Omega \cdot \mathrm{cm}^{2}\right)$ & $\mathrm{CPE} 1\left(\mu \mathrm{F} \cdot \mathrm{cm}^{-2}\right)$ & $\boldsymbol{R} \mathbf{1}\left(\Omega \cdot \mathrm{cm}^{2}\right)$ & $\mathrm{CPE} 2\left(\mu \mathrm{F} \cdot \mathrm{cm}^{-2}\right)$ & $R \mathbf{2}\left(\Omega \cdot \mathrm{cm}^{2}\right)$ \\
\hline Values & 2.56 & 0.038 & 6.86 & 2.52 & $6.38 \times 10^{9}$ \\
\hline
\end{tabular}




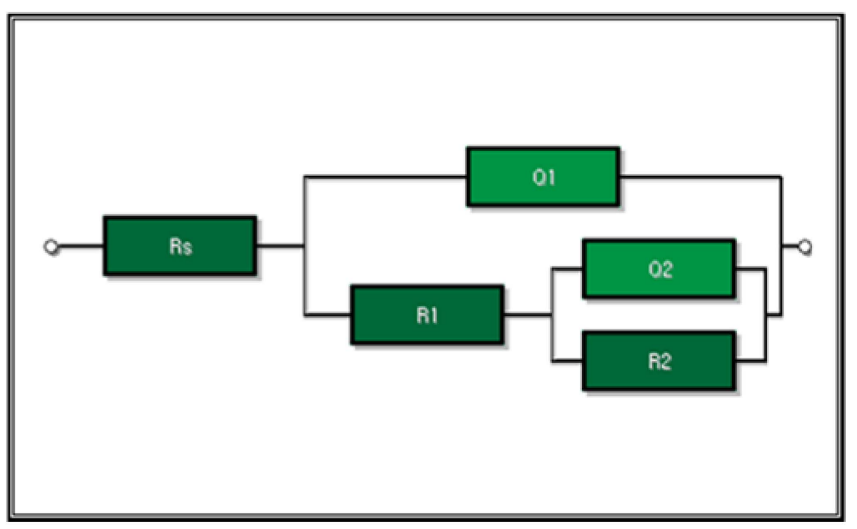

Figure 8. Equivalent circuit model representing the corrosion behavior of the post-laser-treated TZM alloy immersed in $3.5 \% \mathrm{NaCl}$ solution for seven days.

\section{Conclusions}

In order to enhance the oxidation resistance of TZM alloy at high temperatures above $1000{ }^{\circ} \mathrm{C}$, $\mathrm{FeCrAl}$ coating was deposited on TZM alloy with and without the post-laser surface melting process, and the influence of the laser treatment on the corrosion behavior was investigated. The oxidation tests conducted at $1100^{\circ} \mathrm{C}$ in air indicated that oxidation and spalling took place even for the FeCrAl-coated specimens, regardless of whether the post-laser treatment was executed or not, at high temperature. However, the laser process significantly reduced the overall rate of weight loss due to spalling of the coating layer from the substrate.

Meanwhile, diffusion of coating elements occurred from the laser-treated coating layer into the Mo substrate at high temperature, resulting in a reaction layer near the surface. The surface reaction layer mainly consisted of the Fe-saturated Mo phase and the $\mathrm{Fe}_{7} \mathrm{Mo}_{6}$ intermetallic compound. Electrochemical corrosion potentials and current densities for both the as-sprayed and the laser-treated specimens in $3.5 \% \mathrm{NaCl}$ solution were observed to be similar. Finally, an equivalent model for the laser-treated specimen implied that some permeable defects existed in the coating layer.

Acknowledgments: This work was supported by the National Research Foundation of Korea (NRF) grant funded by Korea government (MSIP) (NRF-2012M2A8A5025822).

Author Contributions: J.-M.K. designed the research and wrote the manuscript with help from the other authors; T.-H.H. performed the experiments; J.-M.K., J.-S.P. and H.-G.K. analyzed the data.

Conflicts of Interest: The authors declare no conflict of interest.

\section{References}

1. Alur, A.P.; Chollacoop, N.; Kumar, K.S. High-temperature compression behavior of Mo-Si-B alloys. Acta Mater. 2004, 52, 5571-5587. [CrossRef]

2. Smolik, G.R.; Petti, D.A.; Schuetz, S.T. Oxidation and volatilization of TZM alloy in air. J. Nucl. Mater. 2000, 283, 1458-1462. [CrossRef]

3. Park, J.S.; Kim, J.M.; Cho, S.H.; Son, Y.I.; Kim, D. Oxidation of $\mathrm{MoSi}_{2}$-coated and uncoated TZM (Mo-0.5Ti-0.1Zr-0.02C) alloys under high temperature plasma flame. Mater. Trans. 2013, 54, 1517-1523. [CrossRef]

4. Chakraborty, S.P. Studies on the development of TZM alloy by aluminothermic coreduction process and formation of protective coating over the alloy by plasma spray technique. Int. J. Refract. Met. Hard Mater. 2011, 29, 623-630. [CrossRef]

5. Wang, Y.; Wang, D.; Yan, J.; Sun, A. Preparation and characterization of molybdenum disilicide coating on molybdenum substrate by air plasma spraying. Appl. Surf. Sci. 2013, 284, 881-888. [CrossRef] 
6. Naumenko, D.; Le-Coze, J.; Wessel, E.; Fischer, W.; Quadakkers, W.J. Effect of trace amounts of carbon and nitrogen on the high temperature oxidation resistance of high purity FeCrAl alloys. Mater. Trans. 2002, 43, 168-172. [CrossRef]

7. Hao, S.; Zhao, L.; He, D. Surface microstructure and high temperature corrosion resistance of arc-sprayed FeCrAl coating irradiated by high current pulsed electron beam. Nucl. Instrum. Methods B Beam Interact. Mater. Atoms 2013, 312, 97-103. [CrossRef]

8. Li, C.; Wang, Y.; Wang, S.; Guo, L. Laser surface remelting of plasma-sprayed nanostructured $\mathrm{Al}_{2} \mathrm{O}_{3}-13$ wt. \% $\mathrm{TiO}_{2}$ coatings on magnesium alloy. J. Alloys Compd. 2010, 503, 127-132. [CrossRef]

9. Qian, M.; Li, D.; Liu, S.B.; Gong, S.L. Corrosion performance of laser-remelted Al-Si coating on magnesium alloy AZ91D. Corros. Sci. 2010, 52, 3554-3560. [CrossRef]

10. Sova, A.; Grigoriev, S.; Okunkova, A.; Smurov, I. Cold spray deposition of 316L stainless steel coatings on aluminium surface with following laser post-treatment. Surf. Coat. Technol. 2013, 235, 283-289. [CrossRef]

11. Marrocco, T.; Hussain, T.; McCartney, D.G.; Shipway, P.H. Corrosion performance of laser posttreated cold sprayed titanium coatings. J. Therm. Spray Technol. 2011, 20, 909-917. [CrossRef]

12. Ciubotariu, C.R.; Frunzaverde, D.; Marginean, G.; Serban, V.A.; Birdeanu, A.V. Optimization of the Laser Remelting Process for HVOF-Sprayed Stellite 6 Wear Resistant Coatings. Optics Laser Technol. 2016, 77, 98-103. [CrossRef]

13. Gao, Y.; Xiong, J.; Gong, D.; Li, J.; Ding, M. Improvement of Solar Absorbing Property of Ni-Mo Based Thermal Spray Coatings by Laser Surface Treatment. Vacuum 2015, 121, 64-69. [CrossRef]

14. Kim, H.G.; Kim, I.H.; Jung, Y.I.; Park, D.J.; Park, J.Y.; Koo, Y.H. High-Temperature Oxidation Behavior of Cr-Coated Zirconium. In Proceedings of the LWR Fuel Performance Meeting, Charlotte, NC, USA, 15-19 September 2013; p. 840.

15. Yang, F.; Wang, K.S.; Hu, P.; He, H.C.; Kang, X.Q.; Wang, H.; Liu, R.Z.; Volinsky, A.A. La doping effect on TZM alloy oxidation behavior. J. Alloys Compd. 2014, 593, 196-201. [CrossRef]

16. Leyens, C. Oxidation and Protection of Titanium Alloys and Titanium Aluminides. In Titanium and Titanium Alloys, 1st ed.; Leyens, C., Peters, M., Eds.; Wiley-VCH: Weinheim, Germany, 2003; pp. 187-230.

17. Rajkumar, V.B.; Kumar, K.C.H. Thermodynamic modeling of the Fe-Mo system coupled with experiments and ab initio calculations. J. Alloys Compd. 2014, 611, 303-312. [CrossRef]

18. Verdian, M.M.; Raeissi, K.; Slehi, M. Corrosion performance of HVOF and APS thermally sprayed NiTi intermetallic coatings in 3.5\% NaCl solution. Corros. Sci. 2010, 52, 1052-1059. [CrossRef]

19. Liu, C.; Bi, Q.; Leyland, A.; Matthews, A. An electrochemical impedance spectroscopy study of the corrosion behavior of PVD coated steels in $0.5 \mathrm{~N} \mathrm{NaCl}$ aqueous solution: Part I. Establishment of equivalent circuits for EIS data modelling. Corros. Sci. 2003, 45, 1243-1256. [CrossRef]

20. Kim, W.J.; Ahn, S.H.; Kim, H.G.; Kim, J.G.; Ozdemir, I.; Tsunekawa, Y. Corrosion performance of plasma-sprayed cast iron coatings on aluminum alloy for automotive components. Surf. Coat. Technol. 2005, 200, 1162-1167. [CrossRef]

21. Liu, C.; Bi, Q.; Matthews, A. EIS comparison on corrosion performance of PVD TiN and CrN coated mild steel in $0.5 \mathrm{~N} \mathrm{NaCl}$ aqueous solution. Corros. Sci. 2001, 43, 1953-1961. [CrossRef]

(C) 2016 by the authors; licensee MDPI, Basel, Switzerland. This article is an open access article distributed under the terms and conditions of the Creative Commons by Attribution (CC-BY) license (http://creativecommons.org/licenses/by/4.0/). 